\title{
EL TLCAN AL FILO DE LA NAVAJA: NOTAS PARA UNA PROPUESTA DE RENEGOCIACIÓN
}

\author{
Luciano Concheiro Bórquez \\ María Tarrío García \\ Sergio Grajales Ventura
}

Resumen: Frente a la oposición del gran capital agroindustrial y de laselites gobernantes locales, impulsoras de una modernización empobrecedora y excluyente, las movilizaciones campesinas de los últimos años por una renegociación del capítulo agropecuario forman parte de una lucha por transformar la relación entre el Estado y la sociedad para impulsar el rescate del campo mexicano y fomentar el desarrollo de la economía campesina y de pequeños productores. Aquí se plantean algunas razones por las cuales esta renegociación constituye una condición insoslayable para enfrentar la profunda crisis económica, social y política en que se encuentra sumido el mundo rural.

Palabras clave: apertura comercial, balanza comercial, dependencia alimentaria, precios agrícolas, migración, Acuerdo Nacional para el Campo, renegociación, movimiento campesino.

Luciano Concheiro Bórquez, maestro en Ciencias Sociales, FLACSO, sede México, profesor investigador de la Universidad Autónoma Metropolitana, Unidad Xochimilco (UAM-X), México, jefe del Área de Investigación "Economía Agraria, Desarrollo Rural y Campesinado" del Departamento de Producción Económica (DPE) y docente del Postgrado en Desarrollo Rural (PDR) de la UAM-X, temas de especialización: estructura agraria, apertura comercial y agricultura, nueva ruralidad y movimientos campesinos en México, correo electrónico: concheir@correo.xoc.uam.mx, concheir@yahoo.com. María Tarrío García, doctora en Sociología (especialización en Desarrollo Rural) por la Universidad de París, profesora-investigadora del DPE y docente del PDR de la UAM-X, temas de especialización: desarrollo rural. correo electrónico: mtarrio@cablevision.net.mx.

Sergio Grajales Ventura, licenciado en Economía por la UAM-X, estudiante del PDR de la UAM-X, temas de especialización: apertura comercial y agricultura, nueva ruralidad y movimientos campesinos en México, correo electrónico: sergiograjales@yahoo.com.
Abstract: Opposite to the opposition of the agro-industrial big capital, and of the local ruling elites, promoters of an impoverishing and exclusive modernization, the rural mobilizations of last years for a re-negotiation of the agricultural chapter, they are a part of a struggle for transforming the relation between the State and the society to impel the rescue of the Mexican field and to encourage the development of the rural economy and of small producers. Here there appear some reasons for which this re-negotiation constitutes an unavoidable condition to face the deepeconomic, social and political crisis in which one finds the rural world plunged.

Key words: commercial opening, trade balance, food dependency, agricultural prices, migration, National Agreement on the Field, re-negotiation, rural movement.

Enviado a dictamen: 18 de junio de 2007. Aprobación: 27 de agosto de 2007.

\section{TLCAN: apertura indiscriminada, asimétrica y suicida}

A partir de la crisis de la deuda de inicios de los ochenta, comienza en México un proceso de del modelo sustitutivo de importaciones. La modernización ejecutada por la tecnocracia mexicana bajo la égida del capital transnacional e instituciones como el Banco Mundial (BM), el Fondo Monetario Internacional 
(FMI) y la Organización Mundial de Comercio (OMC) consistía, por un parte, en la reforma estructural de la economía por medio de su apertura, privatización y liberalización y, por otra, en un conjunto de políticas de estabilización macroeconómica.

El proceso de apertura comercial constituiría uno de los pilares fundamentales de la transformación estructural de la economía mexicana. Con base en la teoría neoclásica del comercio internacional y la integración económica, se supuso que la apertura de la economía permitiría que la competencia de las importaciones se encargara de eliminar a los sectores ineficientes y obligaría a los sobrevivientes a modernizarse. El país se especializaría en los sectores que contaran con ventajas comparativas porque, decían, se generaría así un sector exportador dinámico que lograría un crecimiento mayor de la inversión, la producción, el empleo y las remuneraciones.

La apertura tuvo el siguiente ritmo vertiginoso: mientras que entre 1980 y 1985 el grado de apertura de la economía mexicana (que es la suma de las exportaciones más las importaciones, dividida entre el PIB nacional) era de 20\%, para 1986-1993 (período que se inicia con la entrada de México al GATT) era ya de 30\%, y con la firma del TLCAN en 1994 este índice alcanzó 50\% (Villarreal, 2004: 42).

Bajo el TLCAN, la liberalización comercial abarcó la totalidad del sector agropecuario de nuestro país. En un tiempo récord el gobierno mexicano decidió eliminar prácticamente la mayoría de los mecanismos de protección arancelarios y no arancelarios vigentes. En el tratado se acordó la desgravacion inmediata de muchos productos agropecuarios, y se fijó un período de quince años para eliminar la totalidad de las barreras arancelarias, lo que significa que para 2008 todas las importaciones agropecuarias de Estados Unidos y Canadá podrán entrar a nuestro país sin pagar ningún arancel. Se estableció también la eliminación de licencias y permisos previos a la importación, sustituidos por el mecanismo de arancel cuota para el período que tarde la desgravación total de ciertos productos.
Esta agresiva liberalización comercial no tomó en cuenta los estragos que ya estaban causando las políticas de apertura comercial a la economía rural del país. En estimaciones realizadas por el Colegio de Posgraduados sobre la rentabilidad de 74 cultivos en la mitad de la superficie cosechada en el país, en 1992 (7.8 millones de toneladas), se demostraba que en ese año $28.4 \%$ de la superficie analizada tuvo problemas de rentabilidad, lo que significaba que los ingresos por venta de productos fueron menores a los costos de producción medidos a precios privados. ${ }^{1}$ El problema era más grave en el caso de los cultivos estratégicos (maíz, frijol, trigo, arroz, soya y sorgo) donde $26 \%$ de la superficie cosechada analizada (5.9 millones de hectáreas) operaba con pérdidas en 1992 (Rello y Pérez, 1996: 20-21).

Por otro lado, el proceso de liberalización comercial de la agricultura previo a la firma del TLCAN, fundamentalmente desde 1986 hasta 1993, había ocasionado ya un fuerte deterioro en el intercambio comercial con el exterior. Como resultado, el déficit de la balanza comercial de productos agroalimentarios se incrementó significativamente; pasó de un saldo promedio anual negativo de 579 millones de dólares en el período 1982-1986 a uno de 1,388.8 millones de dólares en 1987-1990 (Zermeño, 1996: 60-61).

A pesar de las evidencias anteriores, los negociadores no estuvieron dispuestos a excluir por lo menos los productos más sensibles para la economía mexicana (maíz y el frijol). El gobierno sólo alcanzó a negociar salvaguardas para carne y productos del cerdo, papas, manzanas frescas y extractos de café, pero no para los granos básicos y las oleaginosas, a pesar de ser el subsector más débil dentro del sector agropecuario mexicano. Por su parte, Estados Unidos brindó protección a sus agricultores hortícolas y frutícolas; para ello, estableció licencias de importación temporal y tarifas cuota para una gran cantidad de productos en épocas consideradas clave para la venta de sus cosechas. ${ }^{2}$ Canadá hizo lo propio al determinar excluir sus sectores avícola y de lácteos para protegerlos de posibles riesgos por la apertura comercial (Zermeño, 1996: 63). 
A lo anterior su sumó la pésima y, para muchos, mal intencionada negociación del gobierno mexicano, que no supo o simplemente no quiso defender el establecimiento de mecanismos legales de protección suficientes, de forma tal que se pudiera disponer de instrumentos de revisión, suspensión o moratoria para enfrentar de manera efectiva los posibles estragos a la planta productiva nacional. Por otra parte, la pusilanimidad (en el mejor de los casos) de los negociadores mexicanos los llevó a aceptar mecanismos de resolución de controversias completamente insuficientes (que casi siempre han favorecido a los Estados Unidos) para la defensa de los intereses del país, así como a aceptar la asimetría jurídica del Tratado en relación con el desigual estatuto legal queéste adquiere en México en comparación con el que adopta en Estados Unidos (Gómez y Schwentesius, 2003: 47).

Pero lo más sorprendente fue que las fronteras de México fueron abiertas de manera indiscriminadas a dos países con los que desde entonces México guarda profundas asimetrías, tanto en lo referido a dotación de recursos naturales, tecnológicos y de capital, como en los desiguales costos de producción y de transacción. Lo separaba también el diferente grado de apoyo con subsidios que cada economía brindaba a sus productores, que en México era sensiblemente menor comparado con el de los países del norte.

La Ley de Seguridad Agrícola e Inversión Rural de Estados Unidos, la llamada Farm Bill, aprobada en mayo de 2002, coloca a los productores nacionales en condiciones todavía más desventajosas. Los enormes subsidios que los productores estadounidenses reciben en virtud de esta Ley tienen como efecto principal el abatir los precios internacionales de las cosechas comercializables, con lo que se posibilita la exportación desde Estados Unidos a precios subsidiados (Fanghanel, 2005: 80).

Con la Farm Bill de 2002, los subsidios a la agricultura de Estados Unidos se elevaron a 248 mil 600 millones de dólares para los siguientes diez años, principalmente para algodón, trigo, maíz, soya, arroz, avena, cebada y sorgo. Además, la mayor parte de estos subsidios irán a parar a las manos de ricos terratenientes y a las grandes corporaciones, lo que ha generado ya diversas movilizaciones de protesta de algunas organizaciones de pequeños granjeros estadounidenses (Mittal y Rosset, 2003: 112-113, 115). ${ }^{3}$

Además, cerca de la tercera parte de los subsidios agrícolas que otorga el gobierno de Estados Unidos se destina al maíz. Incluso antes de que entrara en vigencia la nueva Farm Bill, ya se destinaban enormes recursos para subsidiar este cultivo: entre 1995 y 2002 se destinaron al maíz más de 34,000 millones de dólares, el doble de lo canalizado al trigo, el segundo producto que recibe mayores subsidios. Esto le permite a los Estados Unidos deprimir los precios internacionales del grano y venderlo en el exterior por debajo de sus costos de producción, con lo que incurre en la práctica del dumping. Esto es particularmente grave si consideramos que el maíz representa cerca de 40\% de las exportaciones de granos de Estados Unidos a México y que estas importaciones representan ya 30\% de la demanda nacional (Fanghanel, 2005: 87-88).

Todas estas asimetrías en la política de subsidios explican en parte las diferencias tan grandes en productividad agrícola, particularmente, en el sector de granos y oleaginosas. Con excepción del trigo y la semilla de algodón, cultivos en los que México supera el rendimiento de Estados Unidos y Canadá, en los otros nueve cultivos México es superado ampliamente en productividad física de la tierra. Las diferencias son más marcadas en los cultivos de maíz y frijol. En estos casos, la superioridad productiva de Estados Unidos y Canadá es cercana a $70 \%$. Promediando todos aquellos cultivos en que México tiene menor rendimiento, resulta que la superioridad productiva de Estados Unidos es 40\% mayor a la de México, en tanto que la de Canadá es 48\% superior (Flores, 2003: 112).

A esto se agregan los disparos por la espalda del propio gobierno mexicano, que decidió no aplicar los aranceles pactados a las importaciones sujetas a arancelcuota como el maíz, el frijol y la carne de puerco. La 
pérdida de ingresos producto de la evasión del pago de salvaguardas, cuotas compensatorias e impuestos generales a la importación agrícola, principalmente, en las importaciones de manzana, frijol, azúcar, maíz y productos porcinos, bovinos y avícolas se estima en alrededor de $50 \%$ de los volúmenes comercializados (Villarreal, 2004: 249).

Tan sólo en los primeros siete años de operación del Tratado el gobierno dejó de cobrar aranceles por sobrecuota importada de maíz equivalentes a 16.5 millones de toneladas y a 2,684 millones de dólares. Esa cantidad por sí sola hubiera financiado $81 \%$ de todo el gasto público destinado por el gobierno federal en 2001 para fomento agropecuario y forestal, incluido Procampo. En el caso del frijol, las exportaciones estadounidenses por encima de las cuotas pactadas significaron tan sólo en el año 1998 una pérdida fiscal de 41.7 millones de dólares, a la que se agrega 1.6 millones de dólares, producto de las exportaciones canadienses sin cobro de arancel. En este caso, el ingreso perdido hubiera alcanzado para financiar 39\% del Procampo en ese mismo año (Flores, 2003: 148).

A la abrupta apertura comercial se sumó la severa reducción de la participación del Estado en el desarrollo económico del sector agropecuario. Esto implicó, la privatización o desaparición de la columna vertebral de la infraestructura estatal de apoyo a la producción, financiamiento, almacenamiento, comercialización y distribución de productos agropecuarios. Junto a la privatización de los sistemas de riego y de toda la infraestructura de almacenamiento alimentario (ANDSA y BORUCONSA), desaparecieron Fertimex (paraestatal que vendía fertilizantes a precios subsidiados), el Inmecafé (institución pública que apoyaba la producción y comercialización del cultivo), Conasupo y Banrural. Además, se eliminó el otorgamiento de subsidios al agua, fueron restringidos sólo a maíz y frijol los cultivos sujetos a precios de apoyo al productor o de garantía y se redujo el otorgamiento de seguros subsidiados para ayudar a los agricultores a enfrentar los siniestros causados por problemas climatológicos (Yúnez Naude, 1998: 115-116).
Paralelamente, el proceso de cambio estructural pasó también por la reforma de la legislación agraria (Artículo 27 Constitucional y su Ley Reglamentaria), que abrió múltiples vías para el comercio de las tierras ejidales y comunales así como para la concentración de la tierra en grandes unidades de producción (Calva, 1998: 94). La reforma al marco jurídico iba a permitir, según el gobierno, que los grandes grupos de capital pudieran hacer negocios en el sector agropecuario del país, en cualquiera de los subsectores: agrícola, ganadero, forestal e incluso en la administración de las aguas nacionales. No obstante, el gobierno prefiere presentar estos cambios radicales mimetizando los términos, a los que se refiere como correspondientes a "una nueva y trascendente etapa de la reforma agraria” (Concheiro, Tarrío y Diego, 2004: 11).

Para enfrentar el descontento social y los posibles efectos desestabilizadores de estas reformas, el gobierno federal comenzó a organizar una serie de programas de apoyo diseñados bajo una lógica fundamentalmente asistencialista. Uno, Procampo, que transfiere recursos directamente al productor de cultivos básicos y otro, Pronasol, destinado a paliar la pobreza. De manera más reciente surgiría Produce, enfocado fundamentalmente al área productiva (Yúnez Naude, 1998: 115-116).

\section{Los saldos del tratado a trece años de vigencia}

La demanda de renegociación del TLCAN se justifica no sólopor el carácter indiscriminado, asimétrico y suicida de éste sino también porque lejos de resolver parcialmentelos añejos problemas del mundo rural, los hallevado a niveles altamente críticos. Este carácter y estos problemas aunados al retiro de las políticas estatales de fomento explican, en gran medida, los saldos catastróficos del neoliberalismo y del TLCAN para el campo mexicano y sus habitantes.

\section{a) Déficit creciente de la balanza comercial agropecuaria}

Dentro del sector agropecuario, el subsector hortofrutícola constituye el principal rubro de exportación y su 
participación está en ascenso: en tanto que en 1993 representaba 49\%, para el 2005 llegaba ya a 68\% del total de las exportaciones del sector. Sin embargo, si bien es cierto que estas exportaciones han mostrado una acelerada dinámica de crecimiento, ésta ha sido del todo insuficiente para revertir el crecimiento de las importaciones de los cultivos básicos (principalmente de granos y oleaginosas), lo que explica el déficit creciente de la balanza comercial agropecuaria de los últimos años (cuadro l).

Así, la tendencia deficitaria de la balanza comercial agropecuaria y agroalimentaria en los últimos años destaca como el primer gran mentís de las promesas de los promotores del Tratado. Excepto 1995, año en que la devaluación del tipo de cambio en más de 100\% permitió alcanzar un superávit, desde 1993 hasta la fecha, el déficit del intercambio comercial de productos primarios y agroalimentarios, lejos de reducirse, se ha venido incrementando (cuadro 2).

Adicionalmente, el crecimiento de las exportaciones hortofrutícolas ha corrido en paralelo a la disminución de la participación del conjunto de las exportaciones del sector agropecuario dentro del total de las exportaciones no petroleras nacionales: mientras que en 1993 éstas representaban 6.4\%, en el 2005 llegaban apenas 3.3\% (figura 1).

En síntesis, el trueque de cultivos básicos por productos hortofrutícolas que los negociadores mexicanos del tratado impusieron, ha derivado en una pérdida de competitividad externa del sector agropecuario y agroalimentario en su conjunto, así como al interior del sector exportador de México.

\section{b) Dependencia alimentaria}

El tratado reduce significativamente los márgenes para ejercer cierta autodeterminación en el establecimiento de políticas integrales de fomento a la producción nacional de alimentos, que garanticen, en el largo plazo, el abasto oportuno y suficiente de alimentos inocuos y de calidad nutritiva a la población.

Durante los primeros nueve años del Tratado, las importaciones de los diez cultivos básicos crecieron a un ritmo muy superior al de su producción interna. La Tasa Media de Crecimiento Anual (TMCA) del volumen de importación de los diez cultivos básicos fue de $10.4 \%$ y de $13.4 \%$ en los períodos 1994-1997 y 1998-2002, respectivamente; en contraste, la TMCA del volumen de producción fue de $2.5 \%$ y $0.8 \%$ para los mismos períodos (figura 2). Aunque esta tendencia parece estar revirtiéndose en el último cuatrienio, los estragos causados a la economía rural por las crecientes importaciones en los años anteriores han sido significativos.

Así, el promedio anual del volumen de importaciones de los cultivos básicos pasó de 10.8 a 17.4 millones de toneladas del cuatrienio 1994-1997 al cuatrienio 2003-2006. Como puede observarse en la figura tres, el aumento fue más significativo en los granos que en las oleaginosas, al pasar de 5.4 a 10 millones de toneladas en el caso de los primeros, y de 2.9 a 4.1 millones de toneladas en el caso de las segundas.

De esta manera, en los últimos años, el consumo nacional de cultivos básicos es crecientemente cubierto con las importaciones provenientes fundamentalmente de los Estados Unidos. Desde la entrada en vigor del Tratado, tenemos que el promedio anual del índice de dependencia en los diez cultivos básicos pasó de 27 a 38\% del cuatrienio 1994-1997 al cuatrienio 2003-2006. En el caso de las oleaginosas, este índice llegó a 89\% durante elúltimo trienio, aumentando nueve puntos respecto al cuatrienio 1994-1997; en caso de los granos, este índice aumentó su promedio anual en diez puntos durante el mismo período al pasar de 19 a 29\% (figura 4).

Pero la dependencia alimentaria también pone en riesgo la calidad nutricional y sanitaria de los alimentos que consumimos. La importación de productos manipulados biológicamente constituye una situación de intercambio cualitativamente desigual en calidad. La importación de cultivos y alimentos transgénicos ha despertado en varios países la oposición de agricultores, consumidores, científicos y diversos grupos ambientalistas y de la sociedad civil debido a sus posibles impactos negativos sobre los ecosistemas, la biodiversidad y 
la salud (CTCEANC, 2006: 50). Sin embargo, Estados Unidos ha tratado de imponer a los países que son parte del Tratado la eliminación de restricciones y prohibiciones a la introducción de cultivos y alimentos transgénicos; más aún, su objetivo es poder ejercer control y monitoreo de éstos en los países importadores.

Así pues, México recibe sorgo, maíz y frijol transgénicos importados, y, en el caso del maíz, se han encontrado rastros de StarLink, una variedad genéticamente modificada y no autorizada para consumo humano, y que ya ha contaminado las cosechas en algunos estados de la república mexicana. En el caso de México, es de grave riesgo porque es centro de origen del cultivo de maíz y porque puede afectar la existencia de variedades todavía desconocidas (Tarrío y Comboni, 2004: 106).

\section{c) Reducción de los precios agrícolas}

La mayor apertura comercial promovida por el TLCAN permite la importación de grandes volúmenes de granos básicos a bajos precios internacionales, con el consecuente efecto depresivo sobre los precios internos.

Aunque esta tendencia comienza años antes del TLCAN, es claro que es resultado de las políticas neoliberales de las que el Tratado forma parte. Así, durante el período previo al Tratado, en los años 1985-1993, los principales granos y oleaginosas mostraron una reducción de sus precios reales en rangos que van de $21 \%$ para trigo a 57\% para el frijol de soya. Sin embargo, si se observa el período que va de 1985 hasta el año 2000, es decir, incluidos los siete años posteriores a la entrada en vigor del TLCAN, esta reducción es todavía más pronunciada: va de un mínimo de 46\% en trigo hasta un máximo de 72\% en frijol de soya (Flores, 2003: 116, ver cuadro 3).

Pero los deprimidos precios internacionales de las materias primas de origen agrícola no son resultado de la superioridad productiva de los países exportadores en un contexto de libre competencia. Lo que los hace posibles es la supremacía de los Estados Unidos en el mercado mundial, producto de los elevados subsidios a sus productores y de los créditos blandos otorgados a los grandes importadores de sus productos.

Las crecientes importaciones a precios subsidiados tienen como consecuencia principal el abatir los precios internos por debajo de los costos de producción, con lo cual se obliga a los productores de los países subdesarrollados a transferir su excedente productivo, debido a que el precio que reciben por sus productos no remunera el trabajo invertido. En cambio, los quienes sí salen beneficiados son los dueños de la agroindustria importadora de la materia prima, quienes han visto disminuir significativamente sus costos de producción, al tiempo que aumentan sus márgenes de ganancia (Blanca Rubio, 2004: 25).

Las expectativas oficiales de que la importación de granos básicos a bajos precios se traduciría en beneficio de los consumidores finales de alimentos ha resultado un ejercicio más de demagogia, tal y como lo evidencia el incremento significativo en el precio de la canasta básica alimentaria: entre 1994 y 2002 éste se incrementó en 257\% (Gómez y Schwentesius, 2003: 54). En contraste, en el mismo lapso, los productores agropecuarios del país recibieron solamente un incremento de 185\% por sus productos, en tanto que los salarios mínimos aumentaron en sólo 184\%. Esto significa un deterioro significativo de la rentabilidad de la producción agrícola y del poder adquisitivo del salario (Gómez y Schwentesius, 2004: 83).

\section{d) Estancamiento económico, desempleo y pobreza}

Entre los saldos negativos del tratado tenemos que señalar también que la contribución del sector agropecuario al crecimiento económico de México continúa bajando en el período reciente de industrialización exportadora. Esto se refleja en la caída continua de la participación del sector agropecuario en el PIB total, que, desde que el TLCAN entró en vigencia, ha disminuido de manera vertiginosa: de haber representado 7.9\% en 1988 pasó a 5.7\% en 1994 y a 3.4\% en 2006 (figura 5) 
La apertura comercial ha impactado también de manera muy significativa al empleo agropecuario. Mientras que en 1995 la participación de la población ocupada en actividades agropecuarias sobre la población ocupada total era de 23.8\%, para 2006 este porcentaje había descendido a 14.4\% (figura 6). Así pues, el derecho de los campesinos a seguir siéndolo se encuentra severamente amenazado.

En el caso del empleo formal, es evidente también la incapacidad del modelo neoliberal para generar una mayor cantidad de empleos en el sector primario. Así, desde 1997 hasta 2006, el número de trabajadores del sector primario asegurados en el IMSS pasó de 420,442 a 427,924 personas, un incremento de tan sólo 1.8\% en diez años (figura 7). Como porcentaje del total de personas aseguradas, la participación de los trabajadores en el sector primario disminuyó de 3.31 a 2.35\% durante el mismo período (figura 8).

El aumento del desempleo ha venido acompañado de la caída en las remuneraciones promedio del empleo formal, ya que éstas también han disminuido al pasar de un salario de 8.8 dólares por día en 1994 a 8 dólares en 2003 (Villarreal, 2004: 246).

El binomio de bajos empleos y salarios contribuye a explicar el aumento de la pobreza en el campo, que es el sector con los mayores índices de pobreza en el país:

el hecho es que ahora hay más mexicanos pobres que representa $68 \%$ de la población y de ellos, la mitad viven en extrema pobreza. De esos porcentajes, $80 \%$ es de los pobladores rurales (CTCEANC, 2006: 42).

\section{e) Migración}

Finalmente, por estos motivos, en los últimos doce años millones de mexicanos han emigrado a Estados Unidos aun bajoel riesgode perder la vida. Tan sólode 2000 a la fecha, se calcula que salieron 1,500 trabajadores diariamente, la mayoría desplazados de la actividad agropecuaria (CTCEANC, 2006: 42). Además de los daños psicológicos derivados del desarraigo forzado, así como del trato inhumano recibido, la migración tiene como uno de sus principales efectos la desarticulación de la base comunitaria de la sociedad debido a la pérdida de población, y representa la dilapidación del llamado "bono demográfico" para la sociedad nacional (CTCEANC, 2006: 43).

\section{El Movimiento El Campo No Aguanta Más (MEC- NAM) y el Acuerdo Nacional para el Campo: hacia la renegociación del capítulo agropecuario del TLCAN}

La renegociación del TLCAN constituye la demanda de un amplio sector de la población, particularmente de sectores significativos del movimiento campesino e indígena nacional.

El 1 de enero 1994, con la puesta en marcha del Tratado, justo en el momento en que la clase política se regocijaba con la entrada de México al "primer mundo", la insurrección indígena zapatista les echó a perder la fiesta, la que con su memorable "Ya basta" constituyó una denuncia abierta a la reforma del 27 Constitucional, pero también al carácter excluyente del TLCAN, dos de los pilares fundamentales sobre los que se ha querido erigir la modernización neoliberal en el campo mexicano.

Casi nueve años después, a finales de 2002, cientos de miles de campesinos, junto con diversas organizaciones sindicales, agrupados en torno al movimiento "El campo no aguanta más" (MECNAM), protagonizaron una de las movilizaciones más grandes de los últimos años en rechazo al TLCAN y con la exigencia de la renegociación del capítulo agropecuario.

Después de meses de movilizaciones, el MECNAM obliga al gobierno a sentarse a negociar una agenda de política pública propuesta por el propio movimiento. A partir de este ejercicio inédito, las instituciones públicas fueron arrastradas para elaborar conjuntamente un Acuerdo Nacional para el Campo (ANC), signado por el Ejecutivo Federal y diversas organizaciones campesinas, el 28 de abril de 2003. 
El ANC establece muy claramente una serie de compromisos por parte del Ejecutivo Federal en relación con el TLCAN, particularmente lo obliga a: 1) Hacer una evaluación integral de los impactos e instrumentación del TLCAN sobre el sector primario (numeral 47). 2) Aplicar todos los mecanismos legales de defensa del sector agropecuario para combatir los prácticas desleales de comercio internacional (numeral 48). 3) Realizar un análisis de los impactos de la Ley de Seguridad Agropecuaria e Inversión Rural de 2002 de los Estados Unidos y en su caso proceder contra las prácticas desleales (numeral 49). 4) Iniciar de inmediato consultas oficiales con Estados Unidos y Canadá para revisar lo establecido en el TLCAN para maíz blanco y frijol e implementar mecanismos que resguarden los intereses de los productores nacionales y la soberanía y seguridad alimentarias (numeral 50) y 5) suspender la asignación de cupos de importación de maíz blanco, así como iniciar una investigación contra prácticas desleales en el caso del frijol (numeral 51).

Estos elementos constituyen lo que podríamos denominar el "programa mínimo" que el gobierno pactó con las organizaciones campesinas para guiar el proceso de revisión y renegociación del capítulo agropecuario, que, en primera instancia, se acotó a los casos del maíz blanco, frijol, leche en polvo y azúcar. Para estos productos (excepto maíz blanco, para el que se acordó suspender los cupos de importación libres de arancel, excepto en caso comprobado de desabasto) el objetivo era establecer un régimen especial de administración en el que se negociara la no supresión progresiva de las barreras arancelarias sino que se les dé el trato de bienes bajo un régimen permanente de aranceles regulados por cuotas de importación. Sin embargo, hasta la fecha, el Ejecutivo Federal no ha dado cumplimiento al ANC, y las señales enviadas por Felipe Calderón y sus secretarios de Estado no auguran que esto se vaya a cumplir.

Haciendo un balance a más de tres años de su firma, podemos decir que a pesar de sus errores de forma, así como del pragmatismo y de las prácticas clientelares que acabaron por imponerse, el ANC básicamente pone en cuestión aspectos básicos del modelo económico actual, de la globalización impuesta, y particularmente del TLCAN y demás convenios alrededor de éste (Concheiro y Tarrío, 2005). Representa también un intento por reconstituir el pacto social entre el Estado y la sociedad rural que el proceso de modernización neoliberal había venido desmontando en las últimas décadas y que dejaba al Estado despojado de mecanismos efectivos y estables de mediación con las clases, sujetos y actores del mundo rural. En este sentido, el ANC es parte de una serie de procesos que ponen en cuestión al propio Estado y a la transición hacia la famosa democracia en México.

A cuatro años de su firma, el incumplimiento por parte del Poder Ejecutivo Federal de los compromisos establecidos en el ANC, ha llevado a diversas organizaciones campesinas a refrendar su alianza más allá de lo alcanzado por el MECNAM para impulsar una renegociación del Tratado que permita la defensa de la soberanía y seguridad alimentarias.

Algunas vertientes del movimiento campesino, aquellas identificadas con las corrientes neocorporativas, han insistido en el no cumplimiento por parte del Ejecutivo del ANC y han mantenido en pie la demanda por una renegociación del capítulo agropecuario del TLCAN que, entre otras cosas, saque al maíz y al frijol de manera definitiva de dicho Tratado. La Confederación Nacional Campesina (CNC) ha hecho llamados constantes para reconstruir la unidad campesina para relanzar el Acuerdo Nacional para el Campo, ${ }^{4}$ en tanto que organizaciones del Congreso Agrario Permanente (CAP) han insistido en que la política agropecuaria de la actual administración debe excluir al maíz y al frijol del Tratado de Libre Comercio de América del Norte (TLCAN). ${ }^{5}$

La megamarcha del 31 de enero de 2007, convocada por diversas organizaciones sociales, volvió a reunir a diversos sectores del movimiento campesino. Ahí estuvieron, además del CAP y la CNC, ${ }^{6}$ el Comité Nacional de Organismos Rurales Pesqueros (Conaorp) y 
las organizaciones aglutinadas en el Consejo Nacional de Organizaciones Campesinas (Conoc). Nuevamente, además de protestar por el incremento de los productos de la llamada canasta básica y por un programa emergente para la producción sostenida de maíz, la demanda de renegociación del TLCAN volvió a ser el punto de encuentro fundamental. ${ }^{7}$ En la llamada Declaración del Zócalo, junto con la Unión Nacional de Trabajadores (UNT), el Frente Sindical Mexicano (FSM), la Coalición Ciudadana Nacional (CCN) y el Frente Amplio Progresista (FAP), las organizaciones campesinas demandaron, entre otras cosas, la construcción de un nuevo pacto social que tenga como primera condición hacer del campo la prioridad, "revirtiendo su destrucción, apoyando a los pequeños y medianos productores y recuperando la rectoría del Estado, para así fortalecer la soberanía alimentaria". Demandaron también la actualización del ANC y la renegociación del capítulo agropecuario del TLCAN, "excluyendo del mismo los productos alimenticios básicos, estableciendo un programa emergente de fomento a su producción, garantizando la protección al ambiente y a la biodiversidad". ${ }^{\circ}$

Posteriormente, en el marco del cuarto aniversario de la firma del ANC, el Consejo Nacional de Organismos Rurales y Pesqueros (CONORP), el Consejo Agrario Permanente (CAP), la CNC y otras organizaciones agrarias y sindicales, acordaron actuar unitariamente en diversas acciones de protesta en lo que denominaron jornada nacional de lucha por el campo, acciones a las que se sumaron la Unión Nacional de Trabajadores (UNT) y el Foro social Mundial (FSM). En Hidalgo, Nayarit, Chiapas y Zacatecas, diversas organizaciones campesinas afiliadas al CAP se manifestaron en las delegaciones de la SAGARPA para exigir el cumplimiento del ANC. La CNC, por su parte, bloqueó la entrada a la delegación de la Sagarpa en Tepic, Nayarit, y en Zacatecas. Las movilizaciones se extendieron hasta la costa chiapaneca, donde los campesinos bloquearon por cuatro horas las instalaciones de la Sagarpa, de la Secretaría de Desarrollo Social y de Distribuidora Conasupo. ${ }^{9}$
Por otro lado, a mediados de junio de 2007, diversas organizaciones campesinas nacionales y regionales, en conjunto con algunas organizaciones no gubernamentales e instituciones académicas, convocaron a una "Campaña Nacional en Defensa de la Soberanía Alimentaria y la Reactivación del Campo Mexicano" bajo el lema "Sin maíz no hay país...iPon a México en tu boca!".

Varias de estas organizaciones formaron parte del MECNAM y fueron signatarias del ANC. Entre ellas destacan las agrupadas en torno al Consejo Nacional de Organizaciones Campesinas, como la Asociación Mexicana de Uniones de Crédito del Sector Social (AMUCCS), la Asociación Nacional de Empresas Comercializadoras de Productores del Campo (ANEC), la Coordinadora Nacional de Organizaciones Cafetaleras (CNOC), la Coordinadora Estatal de Productores Cafetaleros de Oaxaca (CEPCO), el Frente Democrático Campesino de Chihuahua (FCCH), la Red Mexicana de organizaciones Campesinas forestales (RED MOCAF) y la Unión nacional de Organizaciones Regionales Campesinas Autónomas (UNOFOC), pero también la Coordinadora Nacional Plan de Ayala (CNPA), El Barzón Alianza Nacional de Productores Agropecuarios y Pesqueros (El Barzón-ANPAP) y la Alianza Mexicana por la Autodeterminación de los Pueblos (AMAP).

Esta alianza de organizaciones propone "diez medidas urgentes" para la protección del maíz mexicano, por la soberanía alimentaria y la reactivación del campo mexicano: 1) sacar al maíz y al frijol del TLCAN, instalando un mecanismo de administración de sus importaciones y exportaciones, 2) prohibir la siembra de maíz transgénico, 3) aprobar el derecho constitucional a la alimentación, 4) luchar contra los monopolios del sector agroalimentario, 5) inscribir al maíz mexicano y sus expresiones culturales en la lista de patrimonio oral e intangible de la humanidad, 6) control de precios de la canasta alimentaria básica, garantizar el abasto y crear una reserva estratégica de alimentos, 7) reconocer los derechos de los pueblos originarios y proteger los territorios campesinos y sus recursos naturales, 8) acceso de 
los productores de café a mercados internacionales de mayores precios, 9) impulsar la conservación de bosques y selvas a través de la organización y gestión comunitarias y 10) garantizar el principio de equidad de género en las políticas rurales, así como el reconocimiento pleno de los derechos humanos, ciudadanos y laborales de los jornaleros agrícolas y los trabajadores migrantes.

Finalmente, convocan a participar en la Jornada Nacional de Movilizaciones por la Defensa de la Soberanía Alimentariay la Reactivación del Campo Mexicanoyel Presupuesto Rural 2008 del 12 al 20 de Octubre, que incluye una Marcha Nacional Por la Salvación del Campo. ${ }^{10}$

Desde otra perspectiva, la de un sector del movimiento indígena nacional, miembros de pueblos y comunidades indígenas, de la Red en Defensa del Maíz, al dar a conocer la declaración Defensa territorial del maíz nativo en México, señalaron que "El Tratado de Libre Comercio de América del Norte es un ataque directo contra la economía de los agricultores mexicanos y le abrió la puerta al maíz transgénico, que contaminó muchas regiones maiceras del país". Los indígenas, apoyados por veinte organizaciones de la sociedad civil, entre ellas de Brasil y de Perú, así como de Vía Campesina, rechazaron las leyes que permiten la siembra de transgénicos y de producción de agrocombustibles, las cuales benefician únicamente a las grandes industrias, "convierten los cultivos en máquinas y a los campesinos en trabajadores asalariados". Se pronunciaron en contra del acuerdo que firmó la Confederación Nacional Campesina con Monsanto, al que calificaron como "una traición a los campesinos". Destacaron que su determinación es defender la autonomía alimentaria de los pueblos indígenas, y que "nos mantendremos en resistencia y continuaremos nuestro trabajo milenario de cuidar nuestras semillas y territorios, tanto como nuestras asambleas y costumbres". "

Si tomamos como punto de partida estas propuestas, el análisis del TLCAN tiene un sentido explícitamente político, se trata de modificar una situación que ha llegado a un límite insostenible. Así, una renegociación del capítulo agropecuario del TLCAN que tome en cuenta el conjunto de demandas del movimiento campesino anteriormente señaladas debería incluir, cuando menos, los siguientes elementos: ${ }^{12}$

1. Exclusión definitiva del maíz y frijol del proceso de liberación comercial del TLCAN, ya que dichos productos son estratégicos para la seguridad nacional y la soberanía alimentaria, así como para el respeto a la diversidad étnica, social y cultural de la nación. Además, porque las asimetrías entre los sistemas de producción entre los tres países son prácticamente insalvables. Mientras se negocia y acuerda este punto, los aranceles a las importaciones de maíz y frijol, que rebasen los cupos establecidos, deberán se cobrados estricta e invariablemente.

2. Reintroducción de las restricciones cuantitativas a las importaciones de los productos de las cadenas agroalimentarias consideradas básicas y estratégicas para la seguridad y soberanía alimentarias. Dichos productos son caña de azúcar, arroz, trigo, sorgo, café, huevo, leche, carne de bovinos, porcinos, aves y pescado.

3. Se propone el establecimiento de volúmenes máximos de importación por producto y por cadena agroalimentaria, mediante aranceles-cupo. Paralelamente, debe asegurarse un programa de fomento integral de la producción y productividad por tipo de producto, calidad, región y precio apropiado.

4. Garantizar lainocuidad y el cumplimiento de las normas fitosanitarias para la importación de alimentos. En este punto se requiere revisar y renegociar el capítulo VII del TLCAN, referente a medidas sanitarias y fitosanitarias, para certificar que toda la importación de alimentos, provenientes de Estados Unidosy Canadá, cumpla con los mismos requerimientos de inocuidady seguridad que son exigidos para la exportación de los productos agropecuarios mexicanos a dichos países. Asimismo, para garantizar que se cumplan normas de etiquetado y aplicación del principio precautorio para los productos transgénicos. 
5. Eliminación de prácticas desleales de comercio vía subsidios internos que permitan precios de exportación por debajo de los costos de producción, así como subsidios a la exportación, directos e indirectos (créditos y garantías subsidiados a la exportación) que hagan posible precios de exportación inferiores a los domésticos.

6. Celebrar acuerdos paralelos al TLCAN. Fundamentalmente un acuerdo migratorio que garantice la libre movilidad transfronteriza de la fuerza de trabajo y el goce pleno de los derechos laborales y ciudadanos de ésta. Otro para el establecimiento de fondos compensatorios para regiones, cadenas productivas y sujetos productivos y sociales en desventaja.

Estos elementos se encuentran encaminados a lograr el reconocimiento de las profundas asimetrías entre los países, estableciendo mecanismos de protección para los productos más sensibles del sector agropecuario, así como a compensar los daños ocasionados a millones de productores que han visto deteriorarse gravemente sus condiciones de vida.

Para terminar, recordemos que fue precisamente la convergencia de diversas corrientes del movimiento campesino la que dotó de una enorme fortaleza a las movilizaciones de finales de 2002 e inicios de 2003, las que, finalmente, obligaron al gobierno de Vicente Fox a sentarse a negociar la agenda de política pública propuesta por el MECNAM, el CAP, la CNC y El Barzón, entre otras. En vísperas de la apertura total formal del sector agropecuario y ante el incumplimiento de los aspectos centrales del ANC, esta convergencia parece encontrar un nuevo cauce, más allá de las diferencias (muchas de fondo) que evidentemente existen en el interior de las organizaciones campesinas e indígenas del país. La unidad de este movimiento social heterogéneo, en no pocos puntos irreconciliable, podría colocar al TLCAN nuevamente al filo de la navaja.

\section{Conclusiones}

El TLCAN constituye la profundización del llamado proceso de reforma estructural de la economía nacional por medio de su apertura, privatización y liberalización. Dicho proceso es comandado por el capital transnacional y auspiciado por las agencias internacionales de desarrollo como el Banco Mundial, el FMI y la OMC y puesto en práctica por las elites gobernantes locales.

Esta liberalización a la mexicana eliminó en tiempo récord la mayor parte de los aranceles, permisos y cuotas de importación y todo tipo de barreras no arancelarias, y no quisieron verse los evidentes estragos que ya habían causado a la economía rural del país las políticas de apertura comercial antes de la firma del Tratado. La tecnocracia modernizadora no estuvo dispuesta a excluir cuando menos los productos más sensibles de nuestra economía rural, ni siquiera el maíz o el frijol. Por lo demás, el Tratado carece de mecanismos legales de protección completamente insuficientes para enfrentar de manera efectiva los estragos a la planta productiva nacional, así como de mecanismos de resolución de controversias inútiles para la defensa de los intereses del país.

Las asimetrías existentes entre los países firmantes del Tratado no han hecho más que incrementarse a lo largo de la puesta en práctica del TLCAN, sobre todo a raíz de la Ley de Seguridad Agrícola e Inversión Rural de 2002. A esto se agregan los disparos por la espalda del propio gobierno mexicano, que decidió no aplicar los aranceles pactados a las importaciones sujetas a cuotas, lo que representa pérdidas fiscales enormes para el Estado mexicano que de esta manera subsidia la materia prima de los importadores y enfrenta a los productores nacionales a una competencia desleal avasalladora.

A trece años de vigencia, el TLCAN, lejos de resolver parcialmente los añejos problemas del mundo rural, los ha agudizado de manera crítica. Esta estrategia, aunada al retiro de las políticas estatales de fomento, explica en gran medida los saldos catastróficos del 
neoliberalismo y del TLCAN para el campo mexicano y sus habitantes.

La tendencia deficitaria de la balanza comercial agropecuaria y agroalimentaria ha sido resultado de la incapacidad de las exportaciones hortofrutícolas para compensar el abrumador crecimiento de las importaciones de cultivos básicos.

La profundización de la pérdida de la soberanía y seguridad alimentarias ha sido la consecuencia del crecimiento acelerado de las importaciones de cultivos básicos, las que han venido cubriendo una porción creciente del consumo nacional. El aumento de la dependencia alimentaria es además inseparable del deterioro nutricional y sanitario de los alimentos consumidos en México, sobre todo por la importación de alimentos transgénicos.

Por otro lado, la mayor apertura comercial promovida por el TLCAN permite la importación de grandes volúmenes de granos básicos a bajos precios internacionales, con el consecuente efecto depresivo sobre los precios internos y la pérdida de rentabilidad para los productores nacionales. Este deterioro de los precios ha corrido en paralelo al incremento significativo en el precio de la canasta básica, por lo que los consumidores finales de alimentos también han sido afectados. Es claro entonces que la estrategia de liberalización comercial impulsada por el TLCAN no beneficia ni al productor nacional de alimentos ni al consumidor, sinoúnicamente al capital agroindustrial transnacional asentado en el país, que ve elevar su tasa de ganancia debido a la reducción del costo de la materia prima que utiliza como insumo y a la elevación de sus precios de venta.

Aunado a lo anterior, desde que el TLCAN entró en vigencia, observamos una caída continua de la participación del sector agropecuario en el PIB total y en la población ocupada. Simultáneamente, se ha acelerado la caída en las remuneraciones promedio del empleo formal. Así, el binomio de bajos empleos y salarios contribuye a explicar el aumento de la pobreza en el campo, que es el sector con los mayores índices de pobreza en el país. Por estos motivos, en los últimos años millones de mexicanos han emigrado a Estados Unidos aun bajo el riesgo de perder la vida.

A cuatro años de signado el Acuerdo Nacional para el Campo, el Poder Ejecutivo no ha dado cumplimiento a los compromisos adquiridos. Es vergonzoso e inaceptable que el gobierno sea incapaz de plantear a sus contrapartes el incumplimiento del Tratado en lo referido a las prácticas de comercio desleal derivadas de los apoyos y subsidios extraordinarios otorgados a sus productores, como inaceptable es que se niegue a denunciar los efectos negativos que el Tratado ha tenido para el conjunto del sector primario de México.

Después de trece años de vigencia del TLCAN, los modernizadores neoliberales plantean ahora que "no hay que quedarse a medias" en materia de reformas, pues los saldos negativos del Tratado no se explican por las políticas puestas en marcha, sino por no haberlas puesto en acción de manera más profunda (Villamar, 2004:3). ${ }^{13}$ De este modo, "los actos y negociaciones cuasi secretas de Vicente Fox sobre un TLCAN-PLUS se encaminan a una mayor inserción subordinada del país y a la pérdida definitiva de la soberanía nacional" (Villamar, 2004: 2).

El 2008, año en que el proceso de apertura impulsado por el TLCAN alcanzará la totalidad del sector agropecuario, representa sobre todo un momento de significación política antes que económica. En los hechos, la apertura plena del sector ocurrió hace ya algunos años, pero en términos de las movilizaciones campesinas e indígenas, nos encontramos en la víspera de una fecha política que habrá de poner el Tratado nuevamente al filo de la navaja. La renegociación del capítulo agropecuario del TLCAN puede volver a situarse en el centro de una renovada convergencia política que vuelva a unir en la movilización a diversos sectores del movimiento campesino, y ya existen algunas evidencias de ello. Desde aquellas vertientes identificadas con el neocorporativismo, como el CAP, hasta aquellas que forman parte del nuevo 
Cuadro 1

\begin{tabular}{|c|c|c|c|c|}
\hline \multicolumn{5}{|c|}{$\begin{array}{l}\text { Principales exportaciones e importaciones agrícolas }{ }^{1 /} \\
\text { (millones de dólares) }\end{array}$} \\
\hline \multirow[t]{2}{*}{ Año } & \multicolumn{2}{|c|}{ Exportaciones hortofrutícolas ${ }^{2 /}$} & \multicolumn{2}{|c|}{$\begin{array}{c}\begin{array}{c}\text { Importaciones de cultivos } \\
\text { básicos }^{3 /}\end{array} \\
\end{array}$} \\
\hline & & (a) & & (b) \\
\hline 1993 & 1.386 & 49 & 1.781 & 67 \\
\hline 1994 & 1.486 & 49 & 2.243 & 66 \\
\hline 1995 & 2.000 & 44 & 2.002 & 77 \\
\hline 1996 & 1.920 & 46 & 3.618 & 80 \\
\hline 1997 & 2.004 & 45 & 2.925 & 72 \\
\hline 1998 & 2.304 & 53 & 3.355 & 72 \\
\hline 1999 & 2.401 & 54 & 3.084 & 70 \\
\hline 2000 & 2.515 & 53 & 3.256 & 68 \\
\hline 2001 & 2.691 & 61 & 3.552 & 67 \\
\hline 2002 & 2.640 & 63 & 3.570 & 67 \\
\hline 2003 & 3.275 & 65 & 4.042 & 70 \\
\hline 2004 & 3.808 & 67 & 4.457 & 70 \\
\hline 2005 & 4.077 & 68 & 4.002 & 65 \\
\hline $2006 p /$ & 2.956 & 73 & 2.076 & 64 \\
\hline
\end{tabular}

1/ La cifra de los parciales puede no coincidir debido al redondeo de las cifras.

2/ Incluye legumbres, hortalizas frescas, jitomate, aguacate, cítricos, frutas, frutos comestibles, melón, sandía, papaya, mango, uvas y pasas.

3/ Incluye arroz, míaz, trigo, semillas y frutos oleaginosos, algodón sin cardar ni peinar y sorgo.

p) Cifras preliminares al mes de junio.

(a) Porcentaje sobre el total de las exportaciones agropecuarias.

(b) Porcentaje sobre el total de las importaciones agropecuarias.

Fuente: VI Informe de Gobierno, 2006. 


\section{Cuadro 2}

\begin{tabular}{|c|c|c|c|}
\hline \multicolumn{4}{|c|}{$\begin{array}{l}\text { Balanza comercial agropecuaria y agroalimentaria }{ }^{1 /} \\
\text { (Millones de dólares) }\end{array}$} \\
\hline \multirow{2}{*}{ Año } & \multicolumn{3}{|c|}{ Saldo } \\
\hline & Total & Agropecuario & Agroalimentario \\
\hline 1993 & -1757 & 155 & -1912 \\
\hline 1994 & -2636 & -359 & -2277 \\
\hline 1995 & 1377 & 1995 & -619 \\
\hline 1996 & -973 & -387 & -586 \\
\hline 1997 & -243 & 390 & -634 \\
\hline 1998 & -970 & -304 & -666 \\
\hline 1999 & -688 & 46 & -734 \\
\hline 2000 & -1161 & -47 & -1114 \\
\hline 2001 & -2664 & -847 & -1817 \\
\hline 2002 & -2935 & -1143 & -1792 \\
\hline 2003 & -2981 & -752 & -2229 \\
\hline 2004 & -3115 & -671 & -2444 \\
\hline 2005 & -2552 & -167 & -2384 \\
\hline $2006^{p /}$ & 163 & 830 & -667 \\
\hline
\end{tabular}

1/ La suma de los parciales puede no coincidir con los totales debido al redondeo de las cifras.

$\mathrm{p} /$ Cifras preliminares al mes de junio.

Fuente: VI Informe de Gobierno, 2006.

\section{Cuadro 3}

\begin{tabular}{||r||c|c|c|c|c|c|c|c|c|}
\hline \multicolumn{7}{|c|}{ México: caída del precio real de granos y oleaginosas } \\
$1985-2000(\%)$
\end{tabular}

Deflactado con el INPC (base 1994=100).

Fuente: Juan José Flores Verduzco, 2003: 117. 
Figura 1

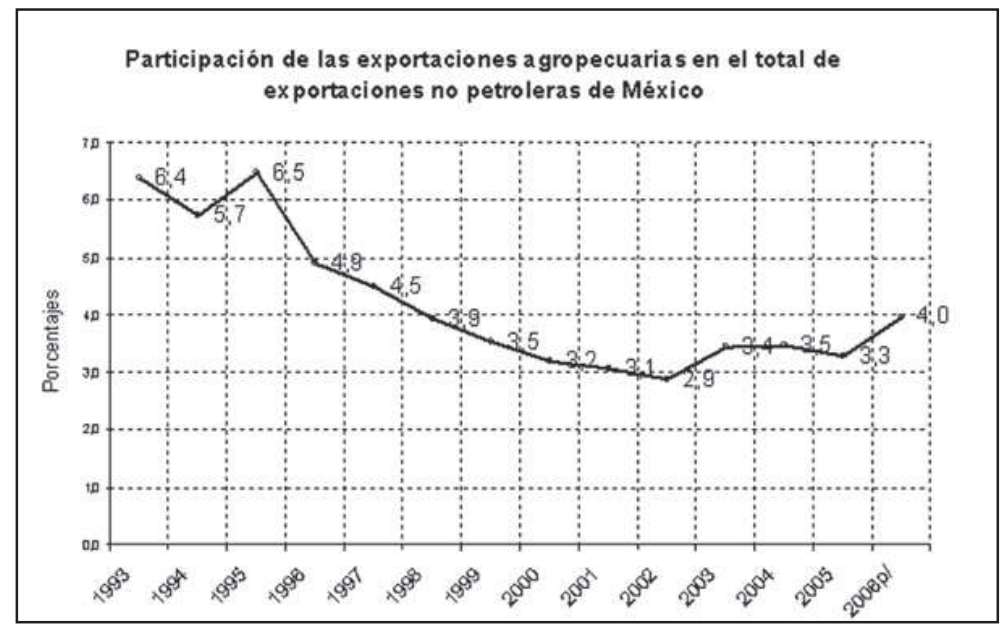

p) Cifras preliminares al mes de junio.

Fuente: Elaborado con base en Vicente Fox, VI Informe de Gobierno, anexo estadístico, Presidencia de la República, 2006.

Figura 2

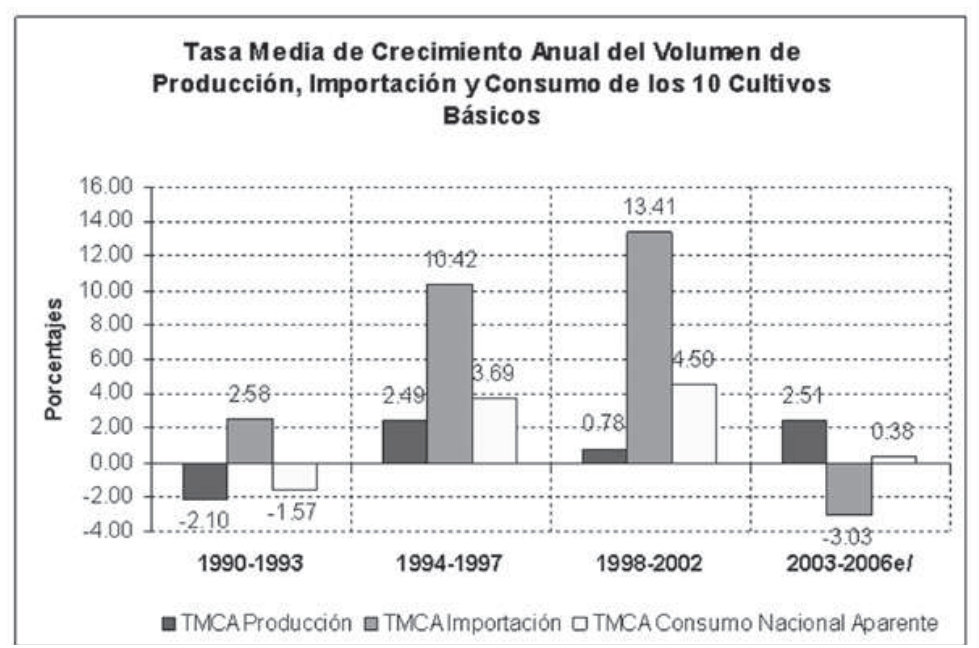

e) Cifras estimadas para el año 2006

Fuente: Elaborado con base en Vicente Fox, VI Informe de Gobierno, anexo estadísti co, Presidencia de la República, 2006. 
Figura 3

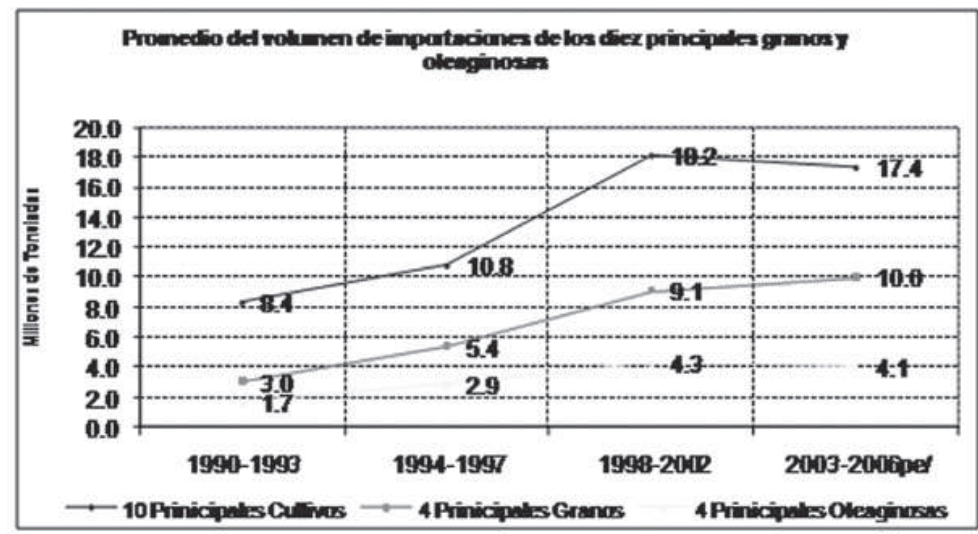

e) Cifras estimadas para el año 2006.

Fuente: Elaborado con base en Vicente Fox, VI Informe de Gobierno, anexo estadís tico, Presidencia de la República, 2006.

\section{Figura 4}

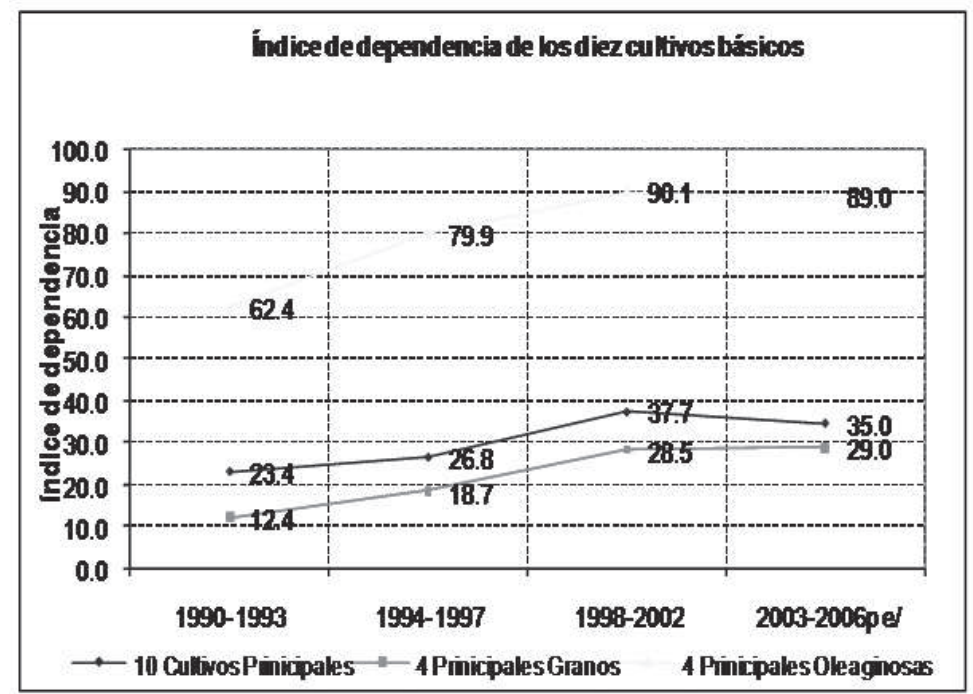

pe) La cifra de 2005 es preliminar y de 2006 es estimada

Fuente: Elaborado con base en Vicente Fox, VI Informe de Gobierno, anexo estadís tico, Presidencia de la República, 2006. 
Figura 5

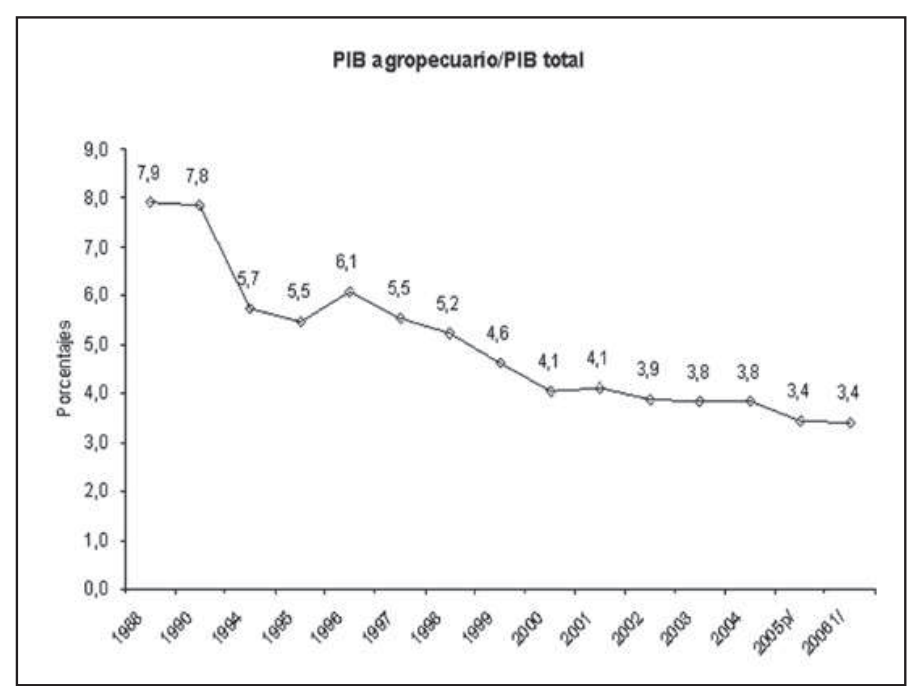

p) Cifra preeliminar.

e) Cifra estimada.

Fuente: Elaborado con base en Vicente Fox, VI Informe de Gobierno, anexo esta dístico, Presidencia de la República, 2006.

Figura 6

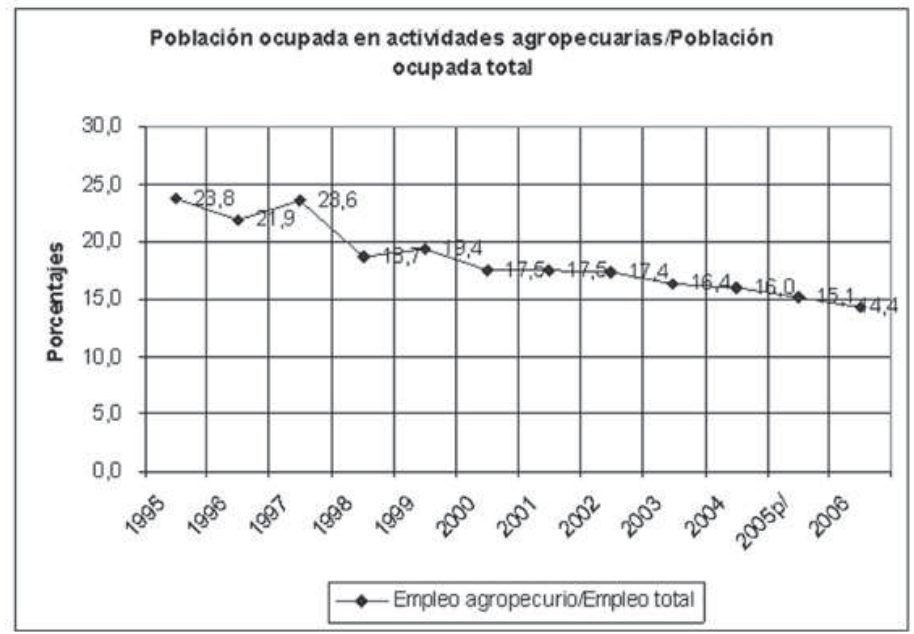

p) Cifra preeliminar.

Fuente: Elaborado con base en Vicente Fox, VI Informe de Gobierno, anexo estadístico, Presidencia de la República, 2006. 
Figura 7

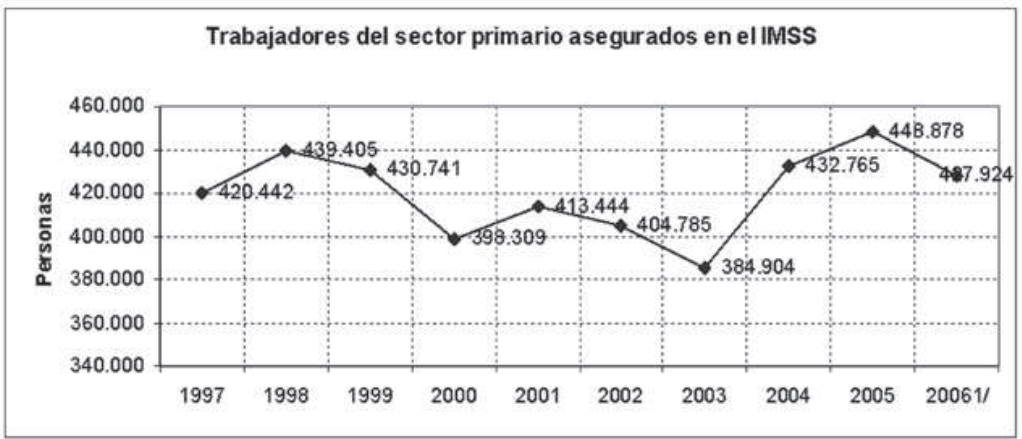

1) Cifra al mes de octubre de 2006

Fuente: Elaborado con base en Vicente Fox, VI Informe de Gobierno, anexo estadístico, Presidencia de la República, 2006.

Figura 8

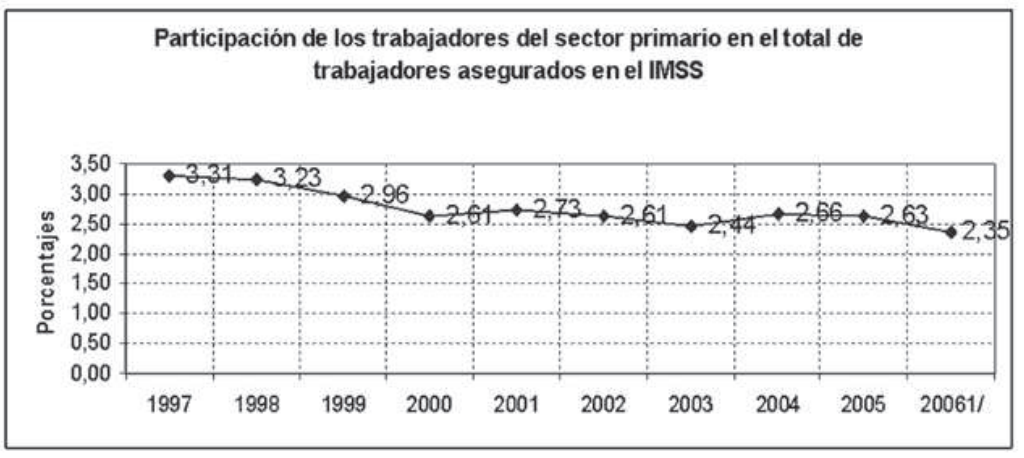

1) Cifra al mes de octubre de 2006.

Fuente: Elaborado con base en Vicente Fox, VI Informe de Gobierno, anexo estadístico, Presidencia de la República, 2006. 
movimiento campesino de organización en redes, como las aglutinadas en torno al Consejo Nacional de Organizaciones Campesinas, todas han mantenido en pie sus demandas de cumplimiento del Acuerdo Nacional para el Campo y de renegociación del capítulo agropecuario del TLCAN. Ambas corrientes han venido desplegando a lo largo de los últimos meses movilizaciones conjuntas en las que demandan, junto con la CNC y algunas organizaciones sindicales, un nuevo pacto social que tenga como prioridad el campo mexicano.

\section{Notas}

${ }^{1}$ Era la primera vez en México que se contaba con informaciones de ingresos y costos que cubrían la mitad de la superficie cosechada.

${ }^{2}$ Así, algunos productos de exportación mexicanos como los pepinos, guayabas, mangos, fresas, tomates cherry, berenjenas y chícharos podrían entrar al mercado estadounidense, pero únicamente en las temporadas del año en que no se cosechasen en Estados Unidos. Este país también estableció salvaguardas para jitomate, cebolla, calabaza y sandía, productos que quedaron sujetos a cantidades máximas de importación durante ciertas temporadas del año.

${ }^{3}$ La famosa Farm Bill incluye, entre otras cosas, créditos automáticos (loan rates) para el maíz y otras cosechas; pagos contracíclicos que protegen a los productores frente a fluctuaciones negativas del mercado; programas garantizados de créditos a la exportación bajo los cuales el gobierno de Estados Unidos garantiza al exportador el crédito al importador (Fanghanel, 2005: 88). La nueva ley también incluye la reinstalación de precios de garantía (Target prices), aumenta recursos para investigación y desarrollo tecnológico y fortalece programas de conservación y producción de combustibles renovables (CTCEANC, 2006: 30).

${ }^{4}$ Pérez Ulloa Matilde, 2007, "Escepticismo de grupos campesinos hacia el PND; no atiende demandas", en La Jornada (página electrónica), lunes 4 de junio, http:// www.jornada.unam.mx/2007/06/04/index.php?section $=$ politica\& article=019nlpol.

${ }^{5}$ Pérez Ulloa Matilde, 2007, "Insisten campesinos en excluir los granos básicos del TLCAN", en La Jornada (página electrónica), martes 15 de mayo, http://www.jornada. unam.mx/2007/05/15/index.php?section=sociedad\& $\&$ arti cle $=049 \mathrm{n} 2$ soc.

6 Sería la segunda ocasión desde que el PAN está en la presidencia de República que la CNC se presenta en una marcha de protesta, y la primera en la que lo hace con su dirigencia nacional en pleno, después de la manifestación de 2003 que finalmente obligó al gobierno de Vicente Fox a la firma del ANC (Elvira Vargas, Rosa, 2007, "Ya estamos viendo las consecuencias de la imposición de un gobierno: AMLO", en La Jornada (página electrónica), jueves 1 de febrero,

http://www.jornada.unam.mx/2007/02/01/index.php?se ction=politica\& $\&$ article $=005 \mathrm{nlpol})$.

${ }^{7}$ Pérez Ulloa Matilde, 2007, "Organismos del campomarcharán el próximo 3l”, en La Jornada (página electrónica), lunes 29 de enero, http://www.jornada.unam.mx/2007/01/29/index.php?section=politica\& $\&$ article $=006 \mathrm{n} 3 \mathrm{pol}$.

8 "La reforma social y democrática del Estado es una tarea fundamental", 2007, en La Jornada (página electrónica) http: //www.jornada.unam.mx/2007/02/01/index.php?sec tion=politica\& 2 article=006nlpol, jueves 1 de febrero.

${ }^{9}$ Carlos Camacho, Jesús Narváez, Rodolfo Villalba, Gerardo Flores, 2007, "Demandan en 4 estados cumplir el Acuerdo Nacional para el Campo", en La Jornada (página electrónica), miércoles 2 de mayo, http://www.jornada. unam.mx/2007/05/02/index.php?section=estados $\&$ arti cle $=036$ nlest.

${ }^{10}$ La Jornada, 21 y 26 de junio de 2007.

${ }^{11}$ Pérez Ulloa, Matilde, 2007, "Defensores del maíz radicalizan su postura”, en La Jornada (página electrónica), viernes 18 de mayo, http://www.jornada.unam.mx/2007/05/18/ index.php?section=sociedad\& $\approx$ article $=050 \mathrm{nlsoc}$.

${ }^{12}$ Los elementos que ahora presentamos son resultado fundamentalmente de las aportaciones que, junto con diversas organizaciones campesinas, universidades

126 Revista LiminaR. Estudios sociales y humanísticos, año 5, vol. V, núm. 2, diciembre de 2007, Tuxtla Gutiérrez, Chiapas. ISSN: 1665-8027 
y centros de investigación hemos realizado en torno al Consejo Técnico Coordinador de la Evaluación del Acuerdo Nacional para el Campo.

${ }^{13}$ Ver las recientes propuestas que Vicente Fox, J. Canales y Ernesto Derbez expusieron a un numeroso grupo de más de 650 "distinguidos" empresarios y funcionarios públicos de Estados Unidos y México en la llamada "Sociedad para la Prosperidad". (Villamar C., Alejandro, 2004, "TLC PLUS: El nuevo desafío a la nación mexicana”, en página electrónica de la RMALC, http://www.rmalc.org.mx/documentos/desafioTLCPlus-AAl.pdf, México).

\section{Bibliografía}

Calva, José Luis, 1998, "La economía nacional y la agricultura de México a tres años de operación del TLCAN", en Rita Schwentesius y Manuel A. Gómez Cruz/ Gary W. Williams (coords.), TLC y agricultura iFunciona el experimento?, Centro de Investigaciones Económicas, Sociales y Tecnológicas de la Agroindustria Mundial (CIESTAAM) de la Universidad Autónoma de Chapingo, Juan Pablos Editor, México, pp. 85-110.

Concheiro, Luciano y María Tarrío, 2005, "El Acuerdo Nacional para el Campo o la Historia de un Movimiento Pendular: entre un pacto por la democracia y un trato clientelar", Mimeo.

—, y Roberto Diego, 2004, "El movimiento El Campo No Aguanta Más frente al Tratado de Libre Comercio de América del Norte", Mimeo.

Consejo Técnico Coordinador de la Evaluación del Acuer do Nacional para el CAMPO (CTCEANC), Centro de Estudios Estratégicos Nacionales (CEEN), 2006, Aportes para la Evaluación y Propuesta de Renegociación del Capítulo Agropecuario del TLCAN (Documento de Trabajo), Cámara de Diputados, LIX Legislatura, México.

Fanghanel, Hernández, 2005, "La liberación del maíz y el frijol en el 2008 en el marco del TLCAN", en Revista Rumbo Rural, Año 1, No. 2, Septiembre-Diciembre de 2005, Centro de Estudios para el Desarrollo Rural y la Soberanía Alimentaria, México, pp. 80-91.
Flores Verduzco, Juan José, 2003, Integración económica al TLCAN y participación estatal en el sistema de innovación tecnológica en granos y oleaginosas en México, UNAM, Plaza y Valdéz, México.

Gómez Cruz, Manuel Ángel y Rita Schwentesius Rindermann, 2003, "Impacto del TLCAN en el sector agroalimentario mexicano. Evaluación a 10 años", en Alberto Arroyo Picard (coord.), Lecciones del TLCAN: El alto costo del "libre" comercio, Alianza Social Continental/Red Mexicana de Acción Frente al Libre Comercio, México, pp. 44-60.

—, 2004, "¿Renegociar el capítulo Agropecuario del TLCAN? Argumentos y Contraargumentos", en Rita Schwentesius y Manuel Ángel Gómez y José Luis Calva Téllez y Luis Hernández Navarro (coords.), ¿El campo no aguanta más?, Universidad Autónoma Chapingo, Centro de Investigaciones Económicas, Sociales y Tecnológicas de la Agroindustria y la Agricultura Mundial, Programa Integración Agricultura Industria (PIAI-CIESTAAM), México, pp. 73-84.

Mittal, Anuradha y Peter Rosset, 2003, Perdiendo nuestra tierra: la ley agrícola de 2002, en Armando Bartra, Cosechas de ira. Economía Política de la Contrarreforma Agraria, Editorial Ítaca, Instituto Maya, A.C., México, pp. 111-131.

Rello, Fernando y Antonio Pérez, 1996, "Liberalización económica y política agrícola: el caso de México”, en Antonieta Barrón y José Manuel Hernández Trujillo (coords.), La agricultura mexicana y la apertura comercial, Facultad de Economía UNAM/UAM A, México, pp. 15-50.

Rubio, Blanca, 2004, "El sector agropecuario mexicano en los años noventa: subordinación desestructurante y nueva fase productiva”, en Blanca Rubio (coord.), El sector agropecuario mexicano frente al nuevo milenio, UNAM/Plaza y Valdéz, México, pp. 17-45.

Tarrío, María y Sonia Comboni, 2004, "Entre la crisis y las movilizaciones. El campo y los campesinos mexicanos a diez años del TLCAN", en Margarita Fernández Ruvalcaba y Magdalena Saleme Aguilar (comps.), 
Dimensión social y humana del crecimiento económico, UAM X, México, pp. 85-128.

Villamar C., Alejandro, 2004, "TLC PLUS: El nuevo desafío a la nación mexicana”, en página electrónica de la RMALC,

http://www.rmalc.org.mx/documentos/desafioTLCPlus-AAl.pdf, México.

Villarreal, René, 2004, TLCAN 10 años después. Experiencia de México y lecciones para América Latina, Editorial Norma, México.
Yúnez Naude, Antonio y Fernando Barceinas, 2004, "El TLCAN y la agricultura mexicana”, en Enrique R. Casares y Horacio Sobarzo (comps.) Diez años del TLCAN en México. Una perspectiva analítica, Fondo de Cultura Económica, México, pp. 61-98.

Zermeño, Felipe, 1996, "La agricultura ante la apertura comercial y el TLC", en Antonieta Barrón y José Manuel Hernández Trujillo (coords.), La agricultura mexicana y la apertura comercial, Facultad de Economía UNAM/UAM A, México, pp. 51-70. 